\title{
A New (Old) Paradigm on Metal Fabrication between the Automobile and the Building Industries
}

\author{
AHMED K. ALI \\ Texas A\&M University
}

This paper provides a serious attempt to build a compelling case, arguing for a new materialism paradigm shift based on structuring a synergistic workflow between the automobile and the building industries. Although the transfer of technology between the two industries has seen an unprecedented increase in the last ten years primarily in robotics technologies and digital fabrication methods, the very basic fundamental aspects of materials supply-chain, fabrication processes, and waste-flow optimization have been overlooked by the design community. The story of making the stamped-aluminum skin of the Aluminum Company of America (ALCOA) building in Pittsburgh (the site of the Material Frontier call discourse) reveals a profound similar synergy between the Pullman company and the building design. The emerging opportunities from such a cross disciplined engagement in materials investigations allows for an informative design process that influences the fabrication territories of both industries. As such, this paper introduces a new methodology in transforming the consistent sized waste-flow of metals from the automobile industry to the building industry addressing an untapped opportunity in design within a time-sensitive circular economy paradigm. The paper presents a thorough review of the ALCOA building design and fabrication processes then introduce a speculative built case study illustrating the conversion from the conceptual to the applied through a series of tactile exterminations.

\section{ALUMINUM AS A "NEW MATERIALISM"}

Aluminum is the third most abundant element after oxygen and silica, its production requires bauxite ore that is high in alumina but low in silica. Two twenty-three-year old scientists, Charles Martin Hall and Paul Heroult, solved the principles of electrolysis contemporaneously and independently. They patented them in the United States and France respectively (Sheller 2014, Skejić, Boko, and Torić, Runge 2018). The HallHeroult process of producing aluminum electrolytically was a combination of their two discoveries. Aluminum is the only light metal which is applied in load-bearing structures and only surpassed by steel in building construction (Skejić, Boko, and Torić). It is used in transportation, electrical, construction, aeronautics, shipbuilding, technical equipment, packaging, antiperspirants, kitchen utensils and many other products. By the late 1990s, the aluminum industry engaged in unusual prototypes, advancing the structural use of aluminum (Buntrock 2016)..Aluminum as a new material, had its profound role in the emergence of new customer markets

\author{
PATRICIA KIO \\ Texas A\&M University
}

based on speedier transport, light packaging and durable goods. Jeffery Schnapp in his essay titled, "The Romance of Caffeine and Aluminum" elaborated on the new material that was, and perhaps still, embraced by twentieth-century industry: aluminum-a material discovered in 1854 but first produced on an industrial scale at the turn-of-the-century mark. Schnapp used the iconic Italian Bialitte Moka Express as an example of a beautiful marriage between the industry and design (Schnapp 2001).

Aluminum and cast iron had transforming cultural impact; although steel and reinforced cement were recurring elements in the building of urban modernism, aluminum added the leavening to make structures light enough to rise far above the ground, put the portability in transport, and the lift into lift off (Sheller 2014). By 2012, aluminum was globally used for nearly $24 \%$ of the total building industry materials, $18 \%$ in cars, $13 \%$ in packaging, $9 \%$ in electric cables, $7 \%$ each in mechanical equipment, appliances and trucks, $2 \%$ in transportation such as airplanes and the remainder for miscellaneous products. In figure 1 , aluminum production increased by over one hundred thousand metric tons for the months of May and June 2018 when compared to production in 2017, expressing increased demand for aluminum.

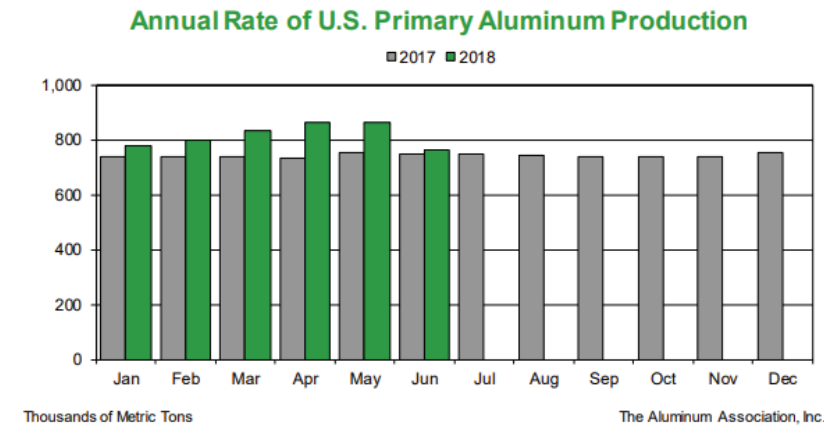

Figure 1. Annual Rate of U. S. Primary Aluminum Production. Source: The Aluminum Association.

The physical properties of aluminum which make it favorable for the building construction industry are its lightness, good mechanical properties, good reflectivity, non-toxicity, good corrosion resistance, non-magnetic state and the absence of arcing during processing. However, its disadvantages include high cost of production, high deformability, high sensitivity to problems of stability, large reduction in heat affected zone during welding and relatively high sensitivity to the effects of fire. 


\section{METALS IN BUILDING FACADES}

Metal has been used for assemblies and ornaments in buildings for more than 9000 years. The use of metals promoted prefabrication and reduced construction time on site. Metal elements combine aesthetic appeal and utility to add a richness to the appearance of buildings and landscapes. It is the permanence of metals that has led to their role as major building components of modern times. Metals have been used for building skins in various applications, sometimes as double skin, blinds or perforated to allow light and ventilation. The use of double skin facades has had a positive impact in energy saving controls. Metal exteriors lend an abstract appeal to buildings, contributing to the identity and symbolic intention as in the case of ALCOA representing an aluminum company. Aluminum was used to symbolize the identity of the aluminum company. A publication in 1956 of The Reynolds Metal Company featured proposals for the structural use of aluminum offered by leading architects such as Walter Gropius, Mies van der Rohe, Marcel Breuer and Pietro Belluschi (Buntrock 2016). Aluminum castings which were mostly decorative, were used for architectural purposes for the Monadnock, Isabella buildings in Chicago, Illinois, USA, the Dome of the Chief Secretary's Building in Sydney, Australia, and the Dome and Roof of the Church of San Gioacchino in Rome, Italy. In most applications, cast elements were bolted to steel framework (Runge 2018).

Exterior cladding was perceived as lightweight, non-load bearing (skin), and used as a membrane for the building, allowing air and daylight to pass through to building occupants. In the 19th century, the use of metal grew substantially, and metal was used for cornices and storefronts. By the 20th century cast iron was used for building fronts primarily for decorative and structural functions. The ironwork could support its weight and usually comprised the entire façade or only the first-floor level. Materials behind the facades were usually brick or wooden systems. The Mesker Brothers were the leaders in the mass production of "housefronts." They used hammers and other tools to decorate metal from the back creating a pleasing appearance on the surface of the metal. Darius Bryjka, an expert on metal facades discovered over twenty-five hundred in over one thousand towns in North America (Winnerman 2012).

The trade catalog was the chief marketing tool for sheet metal and created the link between manufacturers and consumers. Contractors collected brochures from building journals, to show potential customers the possibilities of metal cladding. The buildings with metal exteriors served as live catalogues for their companies.

When the use of metal in interior and exterior cladding began in the late 19th century, sheet metals were not coated but painted on site with bitumen. This developed with technological advancement in the protection of metals with coatings during processing. Pressed galvanized sheet iron and steel facades, cornices, lintels and other components were in widespread demand from 1880s to the 1910 (Gayle, Look, and Waite 1992). In particular, the coatings based on zinc were widely used to protect steel structures against atmospheric corrosion (Ferretti, Traverso, and Ventura 1976). Fifteen distinctive metallic materials serve a wide range of uses from fasteners to elaborate stairs, streetlights and other applications (Gayle, Look, and Waite 1992). Currently, Zahner, a metal company, specializes in the design and construction of metal facades by utilizing digital and analog methods in producing complex and visually compelling facades. Zahner focuses on research and development of digital workflows that improves fabrication delivery, machine coding for manufacturing and opportunities that exist in producing high volumes of highly variable parts (Zahner 2018).

\section{THE ALUMINUM COMPANY OF AMERICA BUILDING (ALCOA)}

The ALCOA Building was constructed between 1951 to 1953. Most parts of the building were fabricated with aluminum. The 120 years old company, is considered the world's largest producer of primary aluminum, operating in 31 countries (Kingsbury 2010). ALCOA was the first company to accept the discovery of Charles Martin Hall and made profits by producing his patents. The firm selected for designing the new headquarters at Pittsburgh was Harrison and Abrahamovitz, an American architectural firm based in New York who were known for their keen interest in the use of stamped metal panels on building facades. The partners, Wallace Harrison and Max Abramovitz proceeded in 1950 to develop a 30-story skyscraper to be a functioning advertisement for the company's wares (Zimring 2017).

ALCOA and its architects drew upon past experiences and dozens of new tests to overcome most of the obstacles posed by design and performance. The construction was a revolutionary use of aluminum in architecture. The unique aluminum walls of the building give the building a lightweight and economical design see figure 2 . The entire facade of the tower is sheathed in stamped aluminum panels. Aluminum was used wherever practical and economical throughout the building. The windows, sashes and frames, heating and ventilating ducts, water piping and wiring system were all made of aluminum. Innovation in the use of aluminum as an alternative material and combined with other materials was evident. Literature suggests that the ALCOA Company in Pittsburgh had a keen interest in construction with sheet metal exterior walls, which was reflected in the design of their headquarters (Yeomans 1998). This was a search for unmatched beauty and utility, a representation of the identity of a material accepted by tradesmen preceded planning and months of laborious designing and field testing. Probably no building in the world has used aluminum so effectively and so economically in its electrical systems as the ALCOA Building. Five new features were explored; exclusive use of aluminum conductor, 
exclusive use of rigid aluminum conduit, dual low-reactance riser buses, the use of all aluminum lighting fixtures designed as integral part of the ceiling panel heating and cooling system, and a lighting system so designed that it can readily be modified to meet changing office arrangements and provide a high lighting level of 35 to 50 foot candles intensity. A crossdisciplinary approach was implemented from the conceptual design to the construction phases of the project with Pullman Standard Car Manufacturing Company in Hammond, Indiana. Innovation is seen in the facade with reversible windows that are easy to clean from the inside. It is pertinent to note that in the construction of the ALCOA building there was a synergistic activity between the automobile and construction industries.

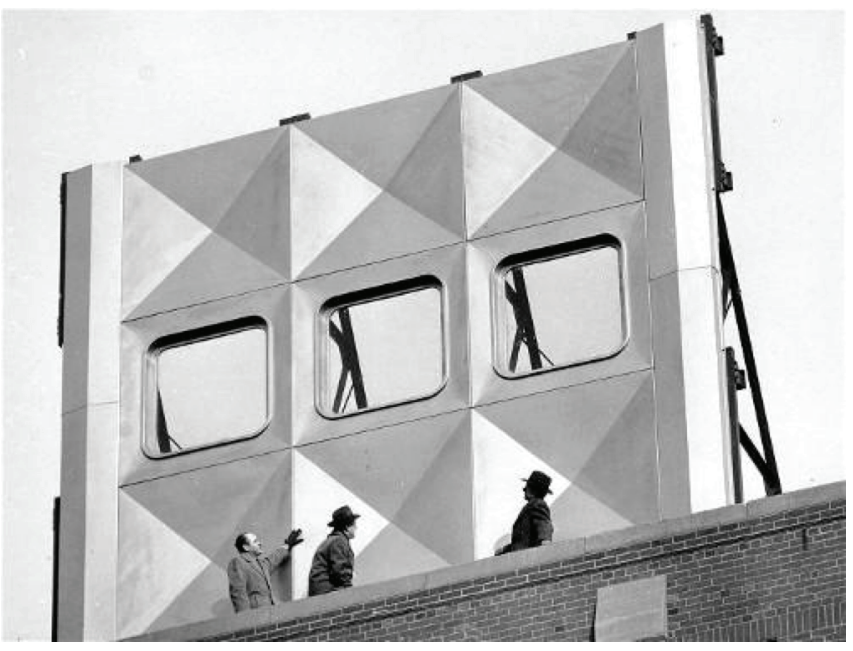

Figure 2. The ALCOA building façade prototype. Source: ALCOA.

\section{THE ALCOA ALUMINUM PANEL}

The ALCOA's Aluminum Research Laboratories at New Kensington, Pennsylvania, carried out several experiments by collaborating with a team of architects, consulting engineers and contractors which provided valuable design decisions. The basic requirements were; the building would be sheathed with weather resistant aluminum paneling system; its windows would be cleaned from the inside and all the thirty floors would be heated and cooled from the ceilings. The choice of a completely weather-tight noncalked exterior wall would make more office space available by its thinness. Several designs for curtain wall paneling systems were submitted until a $6^{\prime} \times 12^{\prime}$ aluminum panel that was mechanically stamped from a $1 / 8$-inch aluminum sheet was selected and produced (ALCOA 1953). The building was sheathed in a continuous run of aluminum panels whose top halves contain 4'-2" X 4'-7" cut-out for the insertion of a reversible aluminum framed window. ALCOA designers worked with the production crew at Pullman Standard Car Manufacturing Company in Hammond, Indiana to fabricate the panels. The panels were shipped from Hammond to the Stolle Corporation in Sidney, Ohio for an electro-chemical finish. The finish was needed to build up aluminum's natural oxide coating. A silicon-bearing alloy liner in the sheet combined with the anodizing process for decoration, gave the panel a permanently iridescent gray color. From Sidney, Ohio, the panels were shipped to a Pittsburgh warehouse where window frames were installed.

The panels were shipped to the construction site from the warehouse and stored in each floor until ready for installation. The one-story-high panels were installed in place by metal brackets which were first bolted to spandrel beams and shimmed into final position by screw jacks. Holes were drilled into the flanged sides of the panels allowing workmen to bring panels into proper elevation in a timely manner. There was no taping or calking of joints, a four-way labyrinth prevented water from escaping to the interior of the envelope. The panels were installed effectively from within the building through a crane sitting on the floor slabs, eliminating the need for expensive scaffolding. Delays in construction caused by weather conditions or wet masonry construction were therefore avoided. Presently, the ALCOA building is a residential apartment building. Floors fourteen through thirty-one have been converted from offices to apartments units (Patgorski 2012).

\section{A FABRICATION-INFORMED DESIGN PROCESS}

At the beginning stage, a long painstaking period of iterations. This was the first attempt at stamping an aluminum panel of such magnitude. The period of iterations involved working out hundreds of designs while considering production problems. There was a challenge on how to find manufacturers to design and construct many new building components in aluminum for the first time to meet basic requirements.

ALCOA designers collaborated with production engineers and fabricators at the Pullman Standard Car Manufacturing Company in Hammond, Indiana. Pullman experimented with modified equipment, and preliminary runs were made to produce the distinctive lightweight curtain wall. Individual panels measured roughly $6^{\prime} \times 12^{\prime}$ and the top half contained a $4^{\prime}-2^{\prime \prime}$ $x 4^{\prime}-7$ " cut-out for the insertion of a reversible, aluminumframed window. The bottom of each panel was depressed into an inverted-pyramid pattern about seven inches deep, see figure 3. The pyramid design could have saved six or more inches of wall thickness if it was fabricated in an almost flat form, but it was chosen primarily for aesthetic reasons. A twostory prototype of the building was erected in Astoria, Long Island and tested for strength, exposure and other qualities. Testing was carried out by the ALCOA team for it's the curtain wall's ability to be lightweight and fireproof. The radiant ceilings, reversible windows and other newly designed building elements were subjected to tests for weather-tightness, operating efficiency and resistance to weathering on the windows. The Climatometer laboratories at Pennsylvania State College also made sure by hundreds of readings that this wall construction would be resistant to the severest extremes of 
temperature and humidity. The ALCOA's Aluminum Research Laboratories at New Kensington, Pennsylvania provided valuable data on radiant-heating ceilings through experiments and problems involving color, design and installation. These events were worked out by a specially appointed building committee. The reversible aluminum windows were fitted with a special inflatable and readily replaceable rubber gasket. forweather tightness.

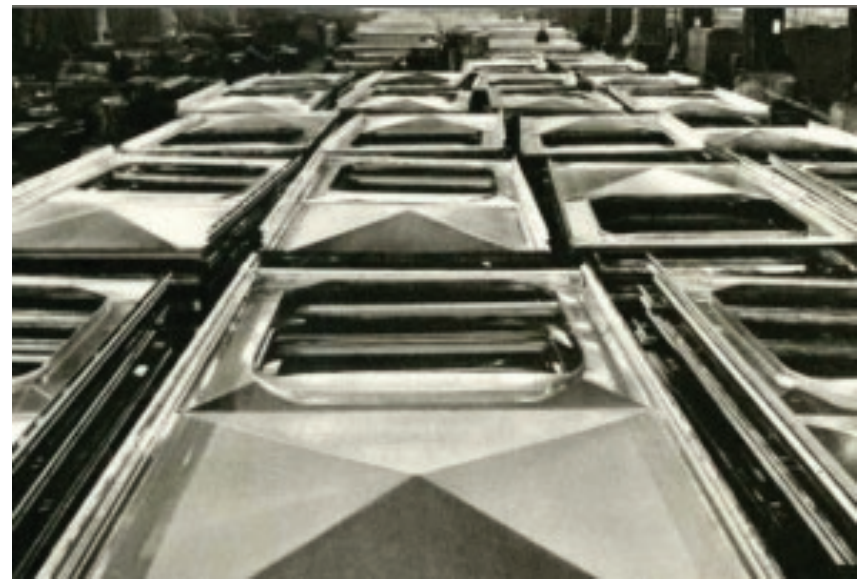

Figure 3. Stamped Aluminum Panels for Alcoa's Modern Skyscraper. Source:(ALCOA 1953.)

The windows were subjected to the mechanical tortures of a "rain room" which measured their resistance to leakage in winds approaching hurricane force. By 1950 when the construction work commenced most of the worrisome problems had been addressed and solved. The use of aluminum contributed to a significant difference in the building's foundation. The foundation piers were smaller and less expensive. The building was the lightest for its size ever built (ALCOA 1953). The thin curtain wall permitted sizable weight saving in its structural steel frame, 6,500 tons of steel were used for the framework.

Though office buildings around were made of masonry, ALCOA took a radical and economical approach in choosing a metal exterior. There was a 30 percent to 50 percent savings over the heavier structural framework required for traditional masonry building. Structural members were materially lighter than those used in traditional buildings.

\section{METAL AS AN AGENT IN INDUSTRIAL ECOLOGY}

The energy crisis in the 1960s and 1970s confirmed that unless industry develops ways to conserve resources, costs could escalate dramatically as resources become depleted (Grant 2000). From the Intergovernmental Panel on Climate Change Report one of the questions raised was, "What changes in lifestyles, behavior patterns and management practices are needed, and by when?" (Pachauri and Reisinger 2007). The production of virgin materials in the metal industry contribute to anthropogenic influences. The introduction of a carbon price was proffered to mitigate carbon related activities and spur the industry to generate processes that reduce their carbon footprint. This study focuses on metals as they are durable and versatile than most building materials. Studies suggested that stone and masonry facades will undergo more deterioration than metals in regions with average temperatures higher than $10^{\circ} \mathrm{C}$. Metal surfaces would have reduced corrosion as surfaces dry up at temperatures higher than $10^{\circ} \mathrm{C}$ (Grøntoft 2011).

Reusing metals proposes a second life for the disposed material. One way to reduce the anthropogenic effects of metals is by the creative reuse of scrap metals as materials for building facades The practice of creative reuse requires an engagement with the emitters of by-products which include the automobile industry to form an ecosystem where the properties of materials are reviewed for decisions regarding their next destination. Material and energy transfers between industries and/or companies create interactions and structures analogous to predator-prey species interactions in an ecological food web (Layton, Bras, and Weissburg 2016).

Creative reuse with existing and future technology after engaging the emitters of industrial by-products will create an ecosystem. An Ecological Network Analysis (ENA) can inform a sustainable organization of material and energy flows among industries that was not previously in the network design space (Layton, Bras, and Weissburg 2016). Industrial symbioses, also known as eco-industrial parks (EIP), occur when multiple firms or facilities in a bounded geographic area achieve higher system efficiency through the exchange of "waste" energy and materials (Reap and Bras 2014).

The in Leadership in Energy and Environmental Design (LEED) 2009 for existing building operations and maintenance has 14 points for use of material on a 100-point scale, 1-2 points are available credits for reuse. The reduction in the use of virgin materials lessens the impacts associated with extraction and processing of virgin materials.(Council 2009) When the amount of reused material in a building is up to $5 \%$, one point is given. $10 \%$ content of reused material accrues 2 points and the use of regional materials within 500 miles of sites has 2 points. The reuse of metals reduces the need for cost intensive recycling and de-galvanizing of galvanized sheet metal.

\section{MATERIAL INVESTIGATIONS}

An example of reuse is the production of building skins with cutouts from the production process of the bodies of automobiles. During stamping cutouts are produced and sold as scrap metal. A plan for reuse will improve the value of the cutouts and create a new life cycle for the material whilst saving energy by replacing the demand for new materials with the harnessed existing byproducts. Scrap metal were obtained from cut-outs during the stamping process at General Motors Lansing Stamping Plant. The cutouts come in various forms and are known as "offal." Eleven different configurations were presented to design facades. Offal meet the standard 
coating requirements required for building construction purposes (2015, Langill). The exercise was carried out to show energy and material savings.

\section{CASE STUDY: FACETED METAL PANELS CLADDING SYSTEM}

The Faceted Metal Panels Cladding System (FMPCS) design proposal highlights the potential link between the building's facade and the car manufacturer by-products in a way to extrapolate the life of scrap material in order to maximize the value of the automobile sheet metal Offal. The design purpose is to creatively reuse the offal cutouts into a faceted building skin. From an analysis carried out on the Offal sheets, the galvanized sheet metal has good properties for processing. It could be folded, bended and rolled, but on the other hand, the irregular shape of offal sheets proposed challenges. These properties and problems in the Offal, especially the offal \#11 offal, presented the ideas and directions of subsequent design. To reduce the cost of the building envelope and to maximize the value of the offal sheet, the design calls for minimizing the intervention of other components on the premise that the envelope's requirement can be responded to and be dealt with efficiently and sufficiently.

The design transformed the irregular shaped offal \#11 into a simple geometry, that makes the panel easier to combine with other units. The design is based on a 3D rhomboid structure that form the basic unit of the skin system, which is folded on the diagonal in 7-degree angle. To retain a whole rectangle as much as possible, a distribution of the offal $\# 11$ in a $200 \mathrm{~mm} x$ $450 \mathrm{~mm}$ rectangle in the center and the remainder on the four sides folds around it. as shown in figure 4 .

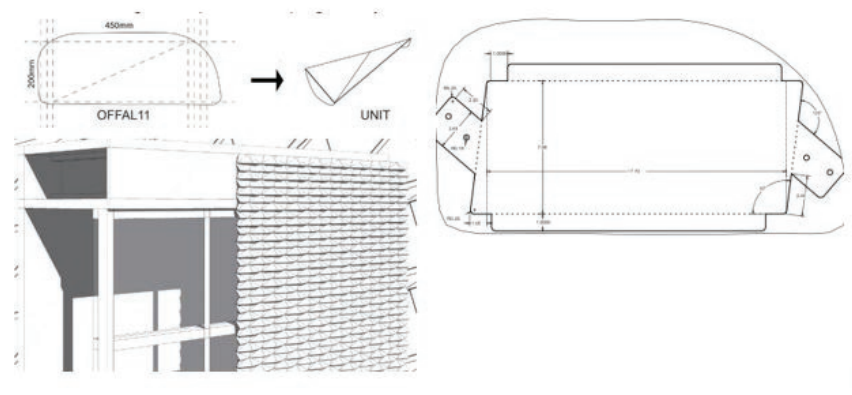

Figure 4. Design of Faceted Metal Panel (left) and maximizing offal sheet \#11 (right). Source: Ma, 2017.

Long sides of rectangle are folded flat to strengthen the single sheet panel, and short sides are folded to form a double lock connection to resist rain water percolation through the building envelope. Cuts were performed by a Computer Numerically Controlled (CNC) method with a waterjet machine and folding was done on a magnetic break.
A comparison of ALCOA panel to the FMPCS, see figure 5, is shown in detail in Table 1. Advantages in transportation, emissions, embodied energy, material carbon emission and costs exist for the proposed FMPSC. The results show $89 \%$ gains in cost of material, $87 \%$ gains in choosing galvanized sheet metal scrap over aluminum scrap due to the thickness, $85.4 \%$ embodied energy gains and $81.1 \%$ less carbon emissions in the production of new material when material is reused. The thickness of FMPCS is $81.9 \%$ less than the ALCOA panels. $78.2 \%$ gains in truck carbon emissions during transportation exist as in this instance, materials are sourced in proximity to site. At equal sizes of $6^{\prime} \times 12$, ' $^{\prime}$ the FMPCS is $48.7 \%$ lighter than ALCOA panel due to their thicknesses. Lastly the ALCOA panel is $99 \%$ bigger in size as it is one huge panel to eighty smaller units of Offal in the FMPCS.
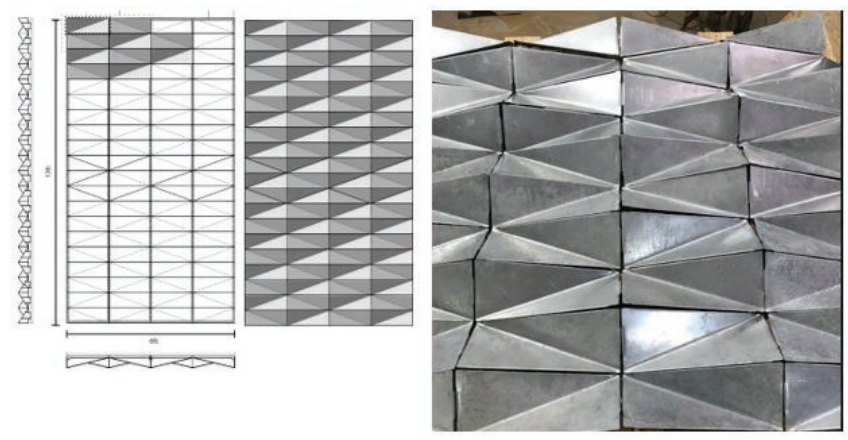

Figure 5. Faceted Metal Panel with units in a 6' $\times 12^{\prime}$ layout Image of constructed Faceted Metal Panel. Source: Authors, 2018.

\section{CONCLUSION}

Designers and architects are well-situated to play a critical role in the circular economy revolution. Design thinking, when correctly applied to address pressing issues such as resource depletion and increasing consumption can provide a paradigm shift in producing a profound collective effect on the built environment. The case of ALCOA building, although 70 years old, resurfaced as a compelling example for why different industries should collaborate in a cross-disciplinary process in addressing material innovation. Although the transfer of technology between the two industries has seen an unprecedented increase in the last ten years primarily in robotics and digital fabrication methods, the very basic fundamental aspects of materials supply-chain, fabrication optimization, and waste-flow have been overlooked. In this paper, a tested example of designing with the automobile sheet metal waste-flow was introduced and compared to ALCOA paneling system. It is through similar engagements between different industries, the physicality of matter with emergent processes of digital design and fabrication will breed a new architecture of effectual tactility. 


\begin{tabular}{|c|c|c|c|}
\hline $\begin{array}{l}\text { Inventory of } \\
\text { energy con- } \\
\text { sumption }\end{array}$ & $\begin{array}{l}\text { ALCOA Alumi- } \\
\text { num Panels } \\
\text { System }\end{array}$ & \begin{tabular}{|l} 
Faceted \\
Metal Panel \\
Cladding \\
System
\end{tabular} & $\begin{array}{l}\text { Efficien- } \\
\text { cy of } \\
\text { FMPCS } \\
\text { (\%) }\end{array}$ \\
\hline Material & Aluminum & $\begin{array}{l}\text { HDG \& ECG } \\
\text { Steel }\end{array}$ & N/A \\
\hline Production & $\begin{array}{l}\text { Stamping \& } \\
\text { bolting }\end{array}$ & $\begin{array}{l}\text { bending \& } \\
\text { bolting }\end{array}$ & N/A \\
\hline No of units & 1 & 80 & 1 \\
\hline $\begin{array}{l}\text { Area of mate- } \\
\text { rial }\end{array}$ & $6^{\prime} \times 12^{\prime}$ & $6^{\prime} \times 12^{\prime}$ & N/A \\
\hline $\begin{array}{l}\text { Mass of mate- } \\
\text { rial }\end{array}$ & $\begin{array}{l}126.4 \mathrm{lb} \text { or } \\
57.3 \mathrm{~kg}\end{array}$ & $\begin{array}{l}120 \mathrm{lb} \text { or } \\
54.43 \mathrm{~kg}\end{array}$ & 48.7 \\
\hline Thickness (mm) & 3.175 & 0.70 & 81.9 \\
\hline $\begin{array}{l}\text { Transportation } \\
\text { Distance }\end{array}$ & 500 miles & 139 miles & 78.2 \\
\hline $\begin{array}{l}\text { Truck Carbon } \\
\text { Emission (kg) }\end{array}$ & $\begin{array}{l}500 x \\
513.5= \\
256.7 \\
2505555513.5 \\
=256.7\end{array}$ & $\begin{array}{l}139 \times 513.5 \\
=71.4\end{array}$ & 78.2 \\
\hline $\begin{array}{l}\text { Embodied En- } \\
\text { ergy for virgin } \\
\text { material (MJ) }\end{array}$ & $\begin{array}{l}57.3 \times 217= \\
12,434.1\end{array}$ & $\begin{array}{l}54.43 \times 39= \\
2,122.8\end{array}$ & 85.4 \\
\hline $\begin{array}{l}\text { Material car- } \\
\text { bon emission } \\
(\mathrm{kgCO} 2)\end{array}$ & $\begin{array}{l}57.3 \times 11.5= \\
659\end{array}$ & $\begin{array}{l}54.43 \times 2.82 \\
=153.5\end{array}$ & 81.1 \\
\hline $\begin{array}{l}\text { Cost of new } \\
\text { material (\$) }\end{array}$ & $\begin{array}{l}@ 0.92 / \mathrm{lb} . \\
=116.3\end{array}$ & $\begin{array}{l}@ 0.12 / \mathrm{lb} . \\
=14.4\end{array}$ & 89 \\
\hline $\begin{array}{l}\text { Cost of scrap } \\
\text { (\$) }\end{array}$ & $@ 0.38 / \mathrm{lb} .=48$ & $\begin{array}{l}@ 0.06 / \mathrm{lb} . \\
=7.2\end{array}$ & 87 \\
\hline
\end{tabular}

Table 1. Comparison of ALCOA Panels System and Faceted Metal Panel Cladding System. Source: Authors, 2018.

\section{REFERENCES}

2015. Standard Specification for Zinc (Hot-Dip Galvanized) Coatings on Iron and Steel Products.

ALCOA. 1953. "Aluminum on the Skyline."

Buntrock, Dana. "Toyo Ito and Masato Araya's Experiments in the Structural Use of Aluminium." The Journal of Architecture 21, no. 1 (2016): 24-54.

Council, US Green Building. 2009. "LEED 2009 for Existing Buildings Operations and Maintenance." Washington, D.C.

Ferretti, L., E. Traverso, and G. Ventura. "Marine Corrosion of Mild Steel in a Thermically Altered Natural Environment." Anti-Corrosion Methods and Materials 23, no. 5 (1976): 3-7.

Gayle, Margot, David W. Look, and John G. Waite. Metals in America's Historic Buildings: Uses and Preservation Treatments. Washington, D.C.: National Park Service, 1992.

Grant, Jill. "Industrial Ecology: Planning a New Type of Industriaul Park." Journal of Architectural and Planning Research 17, no. 1 (2000): 64-81.

Grøntoft, Terje. "Climate Change Impact on Building Surfaces and Façades." International Journal of Climate Change Strategies and Management 3, no. 4 (2011): 374-385. doi: http://dx.doi.org/10.1108/17568691111175669.
Kingsbury, Kathleen. “Recasting Alcoa.” Time 176, no. 19 (2010): Global 1. Langill, Tom. "Galvanizing Standards." Online Seminar. https://galvanizeit.org/ inspection-course/galvanizing-standards.

Layton, Astrid, Bert Bras, and Marc Weissburg. “Designing Industrial Networks Using Ecological Food Web Metrics." Environmental Science \& Technology 50, no. 20 (2016): 11243-11252. doi: 10.1021/acs.est.6b03066.

Patgorski, Leah. 2012. "Former Alcoa Building Could Become your Future Residence." Strada, July 2012. http://www.stradallc.com/2012/07/01/ former-alcoa-bldg/.

Reap, John, and Bert Bras. "A Method of Finding Biologically Inspired Guidelines for Environmentally Benign Design and Manufacturing." Journal of Mechanical Design 136, no. 11 (2014): 111110-111110-11. doi: 10.1115/1.4028303.

Runge, Jude Mary. The Metallurgy of Anodizing Aluminum: Connecting Science to Practice. Cham, Switzerland: Springer, 2018.

Schnapp, Jeffrey T. 2001. "The Romance of Caffeine and Aluminum." Critical Inquiry 28, no. 1 (2001): 244-269

Sheller, Mimi. Aluminum Dreams : The Making of Light Modernity, Mobility Studies. Cambridge, MA: The MIT Press, 2014.

Skejić, D, I Boko, and N Torić. Aluminium as a Material for Modern Structures, GRAĐEVINAR 67 (2015): 1075-1085.

Winnerman, Jim. "Putting Up Fronts." Gateway 32 (2012):56-67.

Yeomans, David. "The Pre-History of the Curtain Wall." Construction History 14 (1998): 59-82.

Zahner. 2018. "The Intersection of Art and Architecture." Accessed Oct. 2018 https://www.azahner.com/.

Zimring, Carl A. Aluminum Upcycled: Sustainable Design in Historical Perspective (Johns Hopkins Studies in the History of Technology). Baltimore: Johns Hopkins University Press, 2017. 